\title{
The ways of business digitalization in global corporations
}

\author{
Vladimir Tretyak ${ }^{1}$, Maria Lyakina ${ }^{2, *}$, and Elena Volkova $^{2}$ \\ ${ }^{1}$ Russian Transport University, Institute of Economics and Finance, 9, ul. Obraztsova, Moscow, \\ Russia, 127994 \\ ${ }^{2}$ Emperor Alexander I St. Petersburg State Transport University, Faculty of Economics \& \\ Managment, Department of Transport Economics. 9, Moscovskiy pr., Saint-Petersburg, Russia, \\ 190031
}

\begin{abstract}
.
Research background: Under the conditions of post-industrial economy, market subjects tend to use digital technologies more intensively. Many authors define digital technologies as innovation, describe possibilities of automatization and try to find out some limitations of smart technologies implementation. In this research, we consider that Industry 4.0 and digital technologies can transform traditional business model radically. That is why, it is very important to highlight the ways of digitalization in business and to justify the choice of the most effective smart technologies during the period of business transformation.

Purpose of the article: to highlight the local ways of digitalization in global corporations and to discover the most effective ones among them.

Methods: in this research, we run comparative analysis of new business models using recent articles in scientific journals and empirical evidence from open sources. Also, we use the results of expert assessments based on depth-in interviews.

Findings \& Value added: the most perspective ways of digitalization in global corporations are highlighted: digital automatization implementation, during which the existent process in traditional business model is digitized; new IT service appearance, that improves the traditional business model; digital transformation of traditional business model into the new one with a digital platform core. A visual model of monitoring the digitalization process within the company is proposed. It is proved that smart technologies can transform business model radically. These technologies affect the structure of companies' supply and can change market structure (including global market) through active company strategy and behavior.
\end{abstract}

Keywords: strategic management; Industry 4.0; global corporations; business model; digitalization

JEL Classification: $L 43 ; L 92 ; R 48$

*Corresponding author: malyakina@mail.ru 


\section{Introduction}

Under the conditions of the development of an information and postindustrial economy, there is a snowballing use of digital technologies by modern agents of the market.

A verifiable hypothesis is to identify certain localized trends of business digitization and determine the most efficient of them in global corporations.

As digital technologies develop and an option to make use of the results of processing large databases is universally embraced, many authors write about digitization of business processes. In the first place, an innovative component of these processes is noted, attempts to assess the impact of the development of digital technologies on the innovative business are made [1]; the prospects of developing various IT technologies, including digital platforms, are analysed both in terms of industrial coverage [2,3], and their global socially economic $[4,5]$ and risk consequences $[6,7]$; new options of the mechanism of functioning of a digital platform or business digital transformation are described [8], both new functions that participants of a value creation chain start to have $[9,10]$, and options of platform economy during and after COVID-19 pandemic are noted [11].

It appears to us that, talking about business digitization, attention should be drawn to a transition to new postindustrial technological setups able to radically change an industrial economic order that became apparent in the course of Industry 4.0 [12]. Therefore, it is important to single out the directions of carrying out business digitization and work out criteria for determining the most efficient of them taking into account a transition from industrial technological setups to the supremacy of information or postindustrial technological setups.

\section{Review}

Digital technologies are massively implemented into economic processes. Global companies distance themselves from paper technologies in business management. Huge databases are created which simplify preparation of managerial documents. Companies conduct work in adapting operating programs and aggregating them into complexes. For large agents of the market who take on the tasks of information processing operations, the product of digitization is software or tools for information processing, i.e. tools of digitization of the previous business models are being set up and, which is the main thing, inside this business. Some companies offer IT services facilitating sales of products or business services. This allows to stabilize flows of incoming orders from consumers and facilitates expansion of supply.

A digital platform organizes business as a work for a pre-known consumer. This allows an association of companies working within a platform not only to guess the demand, but also to shape it. Fraiberger S., \& Sundararajan A. state that participation of clients in P2P platforms is conditioned upon the desire to receive services directly only when they are needed by them (on demand) [13]. In other words, unlike the traditional business model where supply is oriented at guessing the structure of demand, the incipient mechanism of a business model based on digital platforms rests on the other structure of supply implying absence of elements of work for an unknown and free consumer. Forms of final consumer work order reign supreme here, which gives evidence that business digitization can be represented both as digital automation of traditional business, and digital transformation of the nature of business engendering new business models that did not exist in industrial technological setups.

In the course of industrial revolution (first stage) production was mechanized using water and steam. The main driver of the second industrial revolution (within industrial technological setups) was electricity which helped create mass production. The center of 
the third revolution was occupied by electronics and information technologies that automated the production. The fourth industrial revolution seems to be proceeding from the third one. It is characterized by fusion of technologies and abrasion of edges between physical, digital and biological spheres. In other words, Industry 4.0 is a production process equivalent to the customer-related Internet of Things, in which household items, from cars to toasters, will be connected to the Internet [14]. The concept of the fourth industrial revolution was formulated in 2011 by Klaus Schwab, president of the World Economic Forum in Davos. He focused on global changes in humankind in the forthcoming technological setup in the first place. In this revolution, it is people themselves and, respectively, the entire world rather than products that will change most [15].

The evolutional nature of development of technological setups, in our opinion, has the following tendency: from handicraft production where almost all products were unique and created in accordance with a customer's individual requests; through the machine stage of production ensuring mass supply of similar products; to customized mass production able to create products on a mass scale and to satisfy individual requests of buyers.

Simple cooperation and division of labor inherent in pre-industrial or handicraft technological setup lose their dominant position in the industrial society. Factory organization and, somewhat later, conveyor production corresponding to the third and fourth technological setups are mostly widespread here. The latter create a base for postindustrial technological setups using rigid (automatic factories) and flexible automated modules based on using standardized components and expensive creative labor of small numbers of employees.

The global trends are rapidly being formed as postindustrial ones corresponding to the fifth and sixth technological setups inherent not in industrial but in information economy. A distinguishing feature of this process is appearance of digital platforms.

Digital platforms (hereinafter referred to as DP) are one of the types of innovations in business models which appeared within the last two decades. DP means an organization that creates value above all due to ensuring direct interaction between two (or more) various types of affiliated clients № by way of efficient comparison of demand and supply and reduced transaction costs, not on account of ownership and production of physical assets $[16,17]$. DP operates with such added value in order to prevent direct transactions of consumers with suppliers of the platform or their transition to the competing platform where a similar supplier also offers their products or services. In the contradictory union of digital platforms in which employees and users function as isolated units and communities on which sharing economy is based, a number of authors see promising developments of sharing economy [18].

So-called P2P platforms (from English peer-to-peer) or peer-to-peer business models are a particular case of digital platforms. Their functioning implies appearance of new roles inside a business model. This is a role of (a) a platform provider with the help of which exchange and coordination of activities are ensured, this is (b) a different nature of dealing with clients who need products or services, and (c) a different nature of dealing with suppliers of goods and services. Creation of digital platforms is not just digitization of operations of the traditional business model, but also appearance of a new one. A digital platform is a business model provided with high technologies, which creates values by facilitating exchanges between two or more interrelated groups of members.

\section{Methodology}

Research in this article rests on using tools of comparative analysis of conducting digitization which are inherent in the operational practices of modern firms. Besides, the research base is comprised of materials of participatory expert assessments, in relation to 
expected changes in the sphere of business digitization which are obtained as a result of generalizing expert opinions, in the course of conduct of in-depth interviews on the problem of distinguishing features of the transformation being effected in the sphere of business processes digitization.

\section{Results}

As a result of the done research, a statement that it is appropriate to digitize business above all where it facilitates accelerated cessation of supremacy of postindustrial technological setups is justified. Consequently, managerial models should in their development also have a tendency to use the postindustrial basis of production, information technologies in the expectation of transformation of business models of companies.

A visual model can be used to assess the development level of the business digitization in a company process. The essence of the latter consists in getting an opportunity to monitor the process of business digitization. Therefore, it is suggested to follow up the assessment of the condition of the digitization processes in a company by the following three parameters (directions):

- digital automation when the operating process in the traditional business model is digitized;

- appearance of new IT services improving the traditional business model;

- digital transformation of the traditional business model into a new one, the core of which is a digital platform.

Visually, we have a three-sector image the monitoring of which will facilitate conscious management of the processes of business digitization in a company (fig. 1).

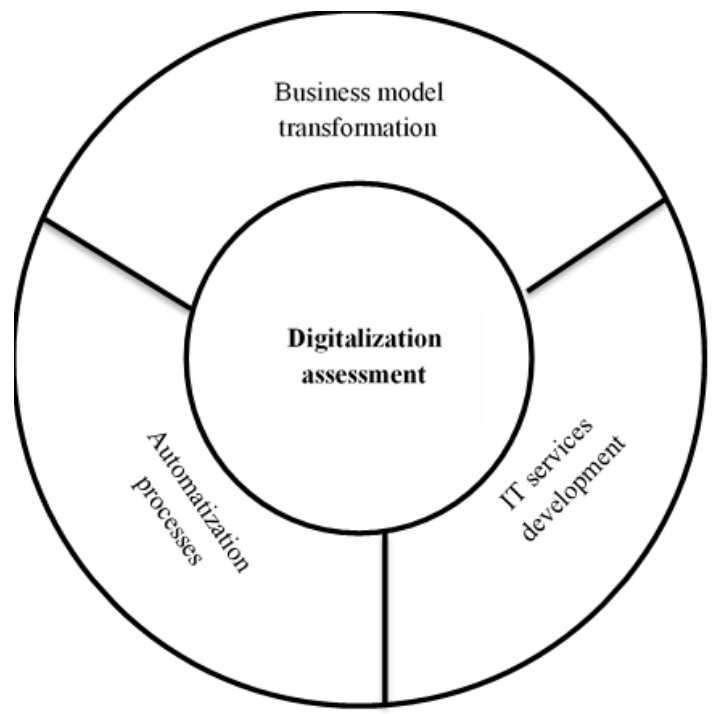

Fig.1. Visual model for digitalization monitoring and assessment in company Source: developed by authors

It appears to us that special research in this sphere can itemize parameters of business digitization, along with that the directions singled out by us will hardly undergo substantial changes in mid-term. In the meantime, the presence of information on changes in the structure of processes of business digitization can give considerable advantages for business and become at the same time a certain depth gage of transformation of the nature of business changing the operating business model. 
Interrogation of the respondents showed that only $28 \%$ of them believe that in the processes of business digitization one should bear in mind differences in the level of tasks which it solves. $72 \%$ of the respondents do not see it necessary. Among the respondents, champions of differentiation of parameters of business digitization, $78 \%$ believe that the parameters offered by us characterize most precisely the essence of the processes which take place in digital transformation of a traditional business model into something new, formed as a digital platform.

All three directions of digitization are characteristic of global corporations. But in practices of companies, digitization of an operating business model dominates. It was established that firm management expects transformation of the nature of companies toward a new, information business model changing traditional forms of management. Whereas in the traditional business model a superior was usually on top for whom the entire remaining pyramid was working, in the information business model the supreme position is occupied by servicing employees, and the superiors and the rest of managers provide them with support. "A manager must pose a question to themselves: Who gives me my paycheck each month? If the answer is my boss or my company, he should be out of business. The only right answer is my buyers".

Graphically this idea is represented in this way (fig. 2).

Consumers

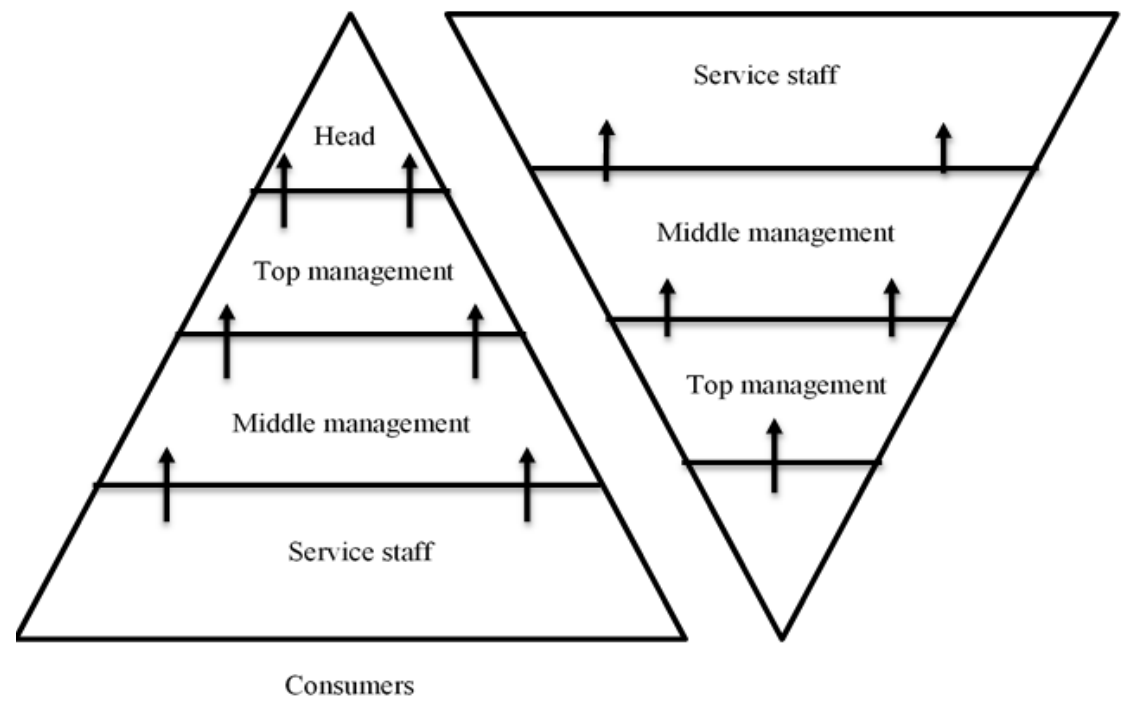

a) traditional company

b) transformed company

Fig. 2. Inverted pyramid of digital business model

Source: [19]

In the left pyramid, all are oriented toward the inside of the company, not paying attention to the consumers. Organizations that are seriously focused on their consumers, as in the pyramid to the right, concentrate on them all their efforts and invest their employees with competences necessary for satisfying any desires of the buyers.

Apart from the high level of technologies, modern companies aim not as much as at increasing sales, as at increasing the growth of a company's shareholder value. Not an increase in the market share on account of attracting more consumers, but acquisition of a greater share of business of large buyers becomes of priority [20]. 
As practice shows, it is appropriate to digitize business first of all where it is accompanied by the deepening of transformation of the nature of the market agent. A traditional firm as an agent of the market carries out a function of redistribution of resources. This function is implemented using a market mechanism: resources from the market are acquired, combined in the process of production, ready products are provided for sales in the market.

It is known that researchers differentiate in this mechanism for redistribution of resources two aspects: the market mechanism proper and a firm's mechanism. If the firm announces that it is looking for employees and organizations able to supply necessary components and materials to it; if it has to search for premises where semi-finished or finished products could be stored, the production process to be conducted, i.e. assembly effected; if the firm will also have to look for organizations which will be able to sell finished products, you are facing a market mechanism of distribution of resources. It becomes in-house only when a contract with people for these types of works implies acknowledgement for the manager of the right to consent of the employees to a certain extent to submit to the production coordinator. It is this phenomenon that E. Prescott and M. Vischer called organizational capital [21]. The consent of the employees to the delegation of their rights to submit to the management fixes a transition to the in-house mechanism of redistribution of resources inherent in the firm. The latter implies the use of relations of power within the boundaries of the firm.

Thus, the presence of a new mechanism of redistribution of resources, differing from the market one, implying the use of relations of power is an essential feature of the nature of a classic or traditional firm, apart from isolation of the goods producer. In other words, a firm is an in-house institution of alternative redistribution of resources among the competing options along with the market mechanism of redistribution of resources.

Presenting the description of the nature of a classical firm operating at the sage of simple commodity production, let us try to review the processes of its formation, achievement of a modern form and the trends of its transformation in the period of supremacy of postindustrial technological setups.

Market strategies of firms are implemented in certain markets and under certain market conditions. Markets are, however, not homogeneous. Most often it is assumed implicitly that a firm functions in a perfect market. Even effective markets ${ }^{1}$ include perfect markets where prices are in equilibrium, where there are a multitude of producers and consumers, where there is no market power, and the markets with operating competition, where certain barriers are assumed. Under such conditions, most firms remaining in the traditional position in a sectoral market as a passive entity on which the external environment acts (above all, the existing sectoral structure, concentration of sellers and buyers, product differentiation, existing non-strategic barriers) act traditionally. Of active entities of the market, on their part, who are able to have impact on the structure of a sectoral market, strategic conduct is characteristic. Active firms having a considerable share in the sectoral market are able to adjust the market mechanism proper under the action of their in-house mechanism, i.e. the strategy is being implemented beyond the boundaries of the firm, as a counterbalance to the market mechanism of redistribution of resources. It is firms that are in the passive trend and acting in the non-effective markets that are able to perform digitization most efficiently in the spirit of an innovative business model.

\footnotetext{
${ }^{1}$ An effective market is a sectoral market the intervention from outside in whose functioning will necessarily lead to a reduction in its performance indicators. An example is a perfectly competitive market
} 


\section{Conclusion}

Parameters for carrying out business digitization in a company have been singled out. They include:

- digital automation, when the operating process in the traditional business model is digitized;

- appearance of new IT services improving the traditional business model; and

- digital transformation of the traditional business model into a new one with the digital platform core.

A visual model of monitoring the process of business digitization in a company has been proposed.

It has been shown that the use of digital platforms able to transform the nature of traditional business models leads, on the one hand, to modifications of offers by companies, and on the other hand, facilitates an option to adjust a market mechanism proper by its inhouse mechanism acting on it. It turns out that a firm's strategy with the use of digital technologies is able to act upon the market mechanism proper beyond the firm's boundaries.

\section{References}

1. Aujirapongpan, S., Songkajorn, Y., Ritkaew, S. (2020). Japan's digital advance policy towards performance in multilateral Asean's innovation business. Entrepreneurship and Sustainability Issues, 8(1), 1081-1094.

2. Lin, H.C., Han, X., Lyu, T. (2020). Task-technology fit analysis of social media use for marketing in the tourism and hospitality industry: a systematic literature review. International Journal of Contemporary Hospitality Management, 8(32), 2677-2715.

3. Au, C.H., Tan, B., Sun, Y. (2020). Developing a P2P lending platform: stages, strategies and platform configurations. Internet Research, 30(4), 1129-1249.

4. Artero, J.M., Borra, C., Gomez-Alvarez, R. (2020). Education, inequality and use of digital collaborative platforms: The European case. Economic and Labour Relations Review, 31(3), 364-382.

5. Pavlov, B.P., Garifullin, R.F, Babushkin, V.M. (2019). Digital transformation of the economy. In K.R. Soliman (Eds.), Education Excellence and Innovation Management Through Vision 2020: 33rd International-Business-Information-ManagementAssociation (IBIMA) Conference Proceedings (pp. 3359-3364). Norristown: IBIMA.

6. Kliestik, T., Valaskova, K., Lazaroiu, G., Kovacova, M., Vrbka, J. (2020). Remaining financially healthy and competitive: The role of financial predictors. Journal of Competitiveness, 12(1), 74-92.

7. Balcerzak, A.P., Pietrzak, M.B., Rogalska, E. (2016), Fiscal contractions in Eurozone in the years 1995-2012: Can non-Keynesian effects be helpful in future deleverage process? In: M.H. Bilgin, H. Danis, E. Demir, U. Can (Eds). Business Challenges in the Changing Economic Landscape, vol.1. Proceedings of the $14^{\text {th }}$ Eurasia Business and Economics Society. Springer International Publishing, 483-496.

8. Park, H., Kim, S., Jeong, Y., Minshall, T. (2020). Customer entrepreneurship on digital platforms: Challenges and solutions for platform business models. Creativity and Innovation Management, 1. 
9. Cennamo, C., Dagnino, G.B., Di, M.A. (2020). Managing digital transformation: scope of transformation and modalities of value co-generation and delivery. California Management Review, 62(4), 5-16.

10. Klimanov, D., Tretyak, O. (2019). Linking business model research and marketing: new network-based approach to business model analysis. Journal of Business \& Industrial Marketing, 34(1), 117-136.

11. Sharma, M., Luthra, S., Joshi, S. (2020). Developing a framework for enhancing survivability of sustainable supply chains during and post-COVID-19 pandemic. International Journal of Logistics-Research and Applications, 4, 1-21.

12. Tretyak, V.P., Sagina, O.A. (2019). Podryv tovarnogo proizvodstva i Forsajt otechestvennoj ekonomiki. [Undermining commodity production and Foresight of the national economy]. In Forsajt «Rossiya»: budushchee tekhnologij, ekonomiki $i$ cheloveka: Materialy V Sankt-Peterburgskogo mezhdunarodnogo ekonomicheskogo kongressa (SPEK-2019), 2 (pp 407-417). St. Petersburg: INIR.

13. Fraiberger, S., Sundararajan, A. (2015, Mar 8). Peer-to-peer rental markets in the sharing economy. SSRN Electronic Journal.

https://papers.ssrn.com/sol3/papers.cfm?abstract_id=2574337

14. Hel, I. (2015, Apr 15). Industry 4.0: what the $4^{\text {th }}$ industrial revolution is? Hi-News.ru. https://hi-news.ru/business-analitics/industriya-4-0-chto-takoe-chetvertayapromyshlennaya-revolyuciya.html.

15. Miller, J. (2017, Jan 16). The defeat of Davos: Are the global 'elite' in retreat? BBC News. https://www.bbc.com/news/business-38632145

16. Hagiu, A., Wright, J. (2015). Multi-sided platforms. International Journal of Industrial Organization, 43, 162- 174.

17. Van Alstyne, M.W., Parker, G.G., Choudary, S.P. (2016). Pipelines, platforms and the new rules of strategy. Harvard Business Review, 94(4), 54-62.

18. De Vaujany, F.-X., Leclercq-Vandelannoitte, A., Holt, R. (2020). Communities versus platforms: the paradox in the body of the collaborative economy. Journal of Management Inquiry, 29(4), 450-467.

19. Temporal, P. (2004) Effective brand management. St.-Petersburg: Neva

20. Doyle, P. (2001). Value based marketing. St.-Petersburg: Piter

21. Prescott, E., Visscher, M. (1980). Organization Capital. Journal of Political Economy, $88,446-461$. 